\title{
Motor unit estimation in a muscle supplied by the radial nerve
}

\author{
C.R. DEFAR I A A N K . T O Y O N A G A \\ From the Department of Medicine (Neurology), McMaster University Medical Centre, \\ Hamilton, Ontario, Canada
}

SUMMARY The number of motor units in a muscle, the abductor pollicis longus (APL), supplied by the radial nerve was estimated. In 40 APL muscles of control subjects, the mean number of motor units was found to be $421 \pm 99$ (SD). Ten patients underwent conventional EMG examination to confirm the clinical suspicion of denervation in radial nerve territory. All presented a significant reduction in the number of motor units in the APL muscle. These results show that this method is useful in the evaluation of muscles supplied by the radial nerve.

A quantal method was described by McComas et al. (1971) for estimating the number of functioning motor units within a human muscle. Weak stimuli of increasing intensity were applied to the nerve innervating the muscle, and the summated electrical responses of single motor units were then compared with the maximum evoked muscular response. An investigation of the number of the motor units in one of the muscles innervated by the radial nerve has not been undertaken previously. The abductor pollicis longus (APL) was chosen because of its relatively isolated and superficial position among the muscles of the forearm. These conditions have permitted the recording of the action potentials without significant interference from other muscles supplied by the radial nerve.

\section{Methods}

Forty APL muscles were studied in 26 healthy subjects of both sexes who were aged between 16 and 43 years and had no evidence of neurological abnormalities. In addition, 10 patients suspected of having denervation of APL were studied; two of these had motor neurone disease, three had radial nerve palsies, three had cervical radiculopathies, and two had brachial neuropathy. In each case, the ambient temperature was regulated at $22-24^{\circ} \mathrm{C}$ and the subjects were examined on a couch with the arm pronated.

Address for reprint requests: Dr C. R. DeFaria, Instituto de Neurologia de Goiania, CP 157, 74000 Goiania, Goias, Brazil. Accepted 23 February 1978
Surface electrodes were used for nerve stimulation and for recording muscle responses. The stimulating electrodes were chlorided silver convex discs, $10 \mathrm{~mm}$ in diameter, which were mounted in a Plexiglass holder so that their centres were $30 \mathrm{~mm}$ apart. The recording electrodes were constructed out of $6 \mathrm{~mm}$ wide silver foil; the stigmatic and reference electrodes were $22 \mathrm{~mm}$ in length while the earth (ground) electrode measured $60 \mathrm{~mm}$. The electrodes were coated with a conducting jelly, and the stigmatic electrode was placed so as to cover the endplate zone, which was found to lie transversely across the muscle some $70 \mathrm{~mm}$ proximal to the styloid process of the radius (Fig. 1). The reference electrode was wrapped around the middle phalanx of the little

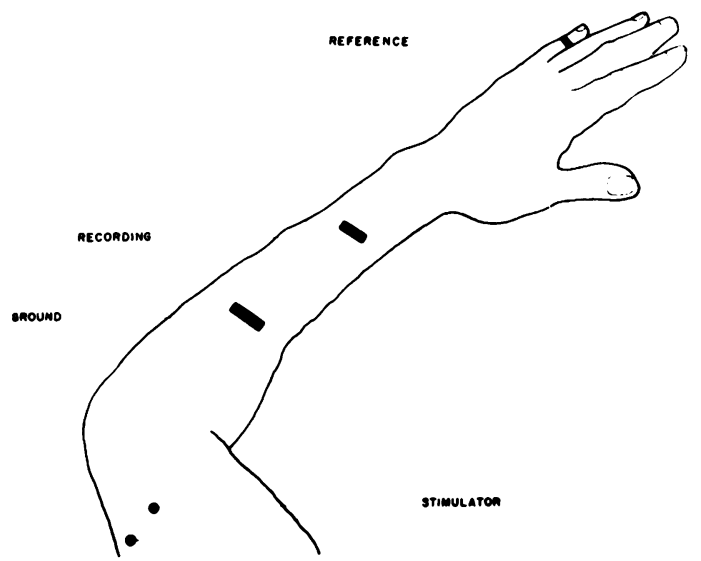

Fig. 1 Electrode positions for motor unit counting in the abductor pollicis longus muscle. 
finger. The ground electrode was placed on the forearm between the stimulating and stigmatic electrodes. The electrical stimuli were rectangular voltage pulses, $50 \mu \mathrm{s}$ in duration, which were delivered to the radial nerve in the lower part of the spiral groove from model 3072 stimulator, itself controlled by a model 3290 digital timing device (Devices Ltd). The evoked responses were fed into a low-noise amplifier, using $3 \mathrm{~dB}$ frequency response cuts at $2 \mathrm{~Hz}$ and $1 \mathrm{kHz}$. The responses were displayed on a variable persistence cathode ray oscilloscope (Hewlett-Packard model $141 \mathrm{~B})$.

\section{Results}

\section{CONTROL SUBJECTS}

Figure 2 (left) illustrates the evoked responses in the APL muscle of a control subject. In the upper part of the figure (a), the increments are shown, their summated potential measuring $144 \mu \mathrm{V}$ peakto-peak, for nine motor units. The maximum evoked response ( $M$ wave) is shown below (c), and is $5.3 \mathrm{mV}$ in amplitude. Division of the amplitude of the maximum $\mathbf{M}$ wave by the average motor unit potential $16 \mu \mathrm{V}(=144 / 9)$ yields an estimate of 281 motor units. Figure 2 (right) illustrates one patient who had only five motor units. The supramaximal stimulation evoked the response which corresponds to the fifth motor unit.
As Ballantyne and Hansen (1974) have pointed out, calculation of motor units may also be performed using response areas (voltage $\times$ time) rather than amplitudes. In a few instances, estimates based on response areas were made using a simple technique which involved projection of the responses on to squared paper. The area results were in reasonable agreement with those based on amplitude; for example, values of 162 and 183 units respectively were obtained for the responses of one patient, who had the calculation done by the two different methods.

The mean estimated number of motor units in the 40 control muscles was $421 \pm 99$ (SD) with a range of 272-666; the mean increment was $13.3 \pm 4.9 \mu \mathrm{V}$. The $\mathrm{M}$ waves evoked by supramaximal stimulation had a mean value $5.5 \pm$ $1.9 \mathrm{mV}$.

\section{PATIENTS}

Ten patients with clinical evidence of either radial nerve lesions or C7-C8 root lesions were submitted to APL motor unit counting and the results are given in Tables 1-4. Three patients with unilateral radial nerve palsy (Table 1) all presented a reduced number of motor units in the APL muscle on the affected side compared with the unaffected APL and other muscles innervated by the median or ulnar nerves. In regard to motor neurone disease,

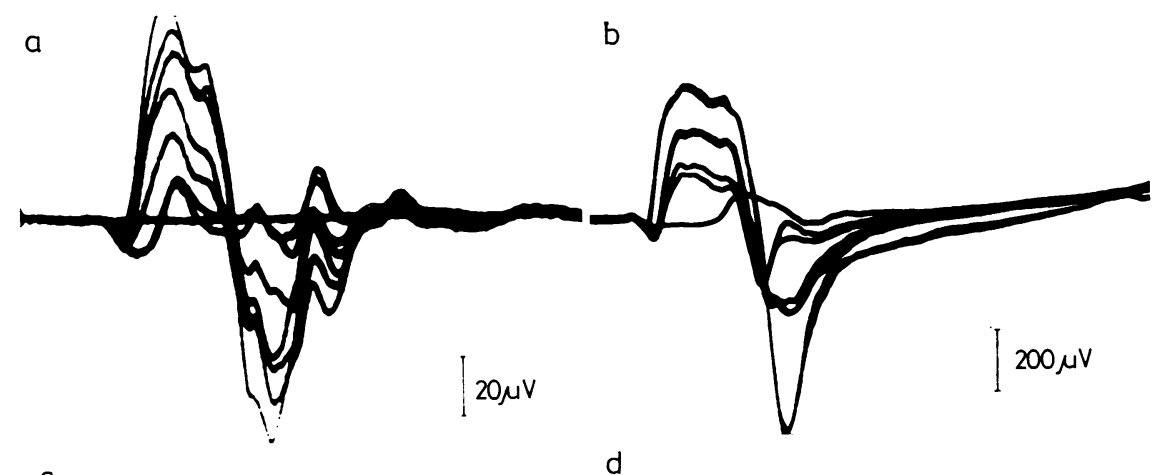

C

d

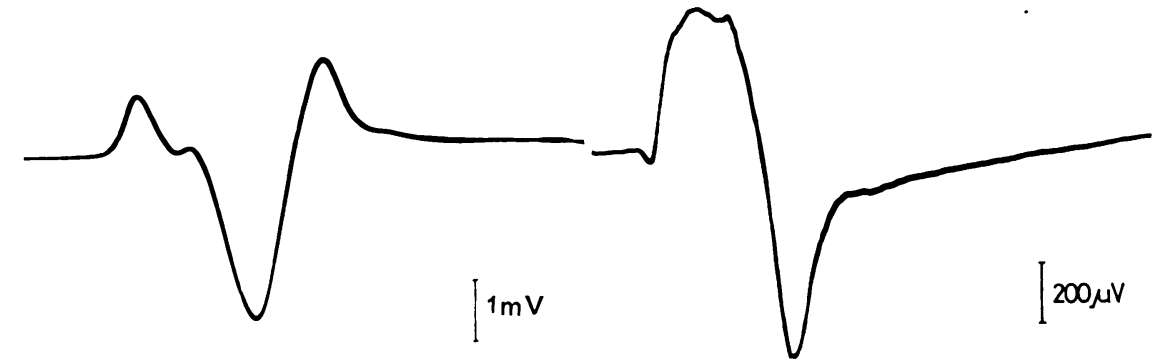

Fig. 2 (a) Superimposed increment of nine motor units in a normal control subject; (b) increments of five motor units in a patient with severe denervation; (c) $M$ wave in the normal control subject; (d) $M$ wave in the patient. 
Table 1 Radial nerve palsy-three patients

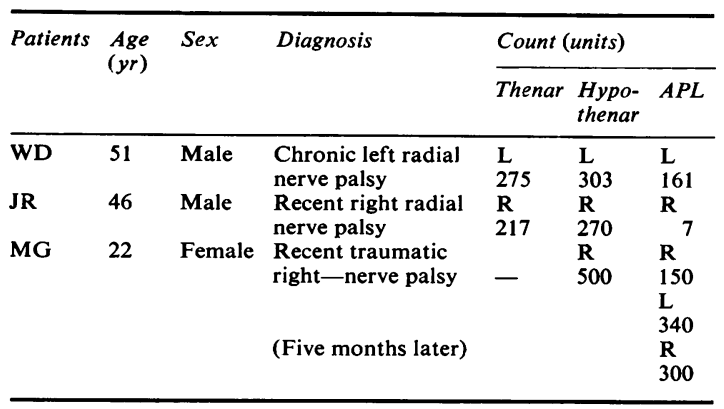

two patients with weakness of the upper limbs provided evidence that the APL shares the same involvement as the other distal muscles (Table 2). In two patients with unilateral brachial plexus lesions (Table 3), the number of motor units in the APL was reduced when $\mathrm{C} 7-\mathrm{C} 8$ roots were clinically affected. Three patients with either unilateral or bilateral cervical root compression were examined to show whether or not the APL's nerve supply was involved (Table 4).

The mean increment was $46.89 \pm 52.19 \mu \mathrm{V}$ (SD) which was over three times higher than that in the control group (Fig. 3).
Tab!c 2 Motor ncurone disease-two patients

\begin{tabular}{|c|c|c|c|c|c|c|}
\hline \multirow[t]{2}{*}{ Patients } & \multirow{2}{*}{$\begin{array}{l}\text { Age } \\
(y r)\end{array}$} & \multirow[t]{2}{*}{ Sex } & \multirow[t]{2}{*}{ Diagnosis } & \multicolumn{3}{|c|}{ Count (units) } \\
\hline & & & & Thenar & $\begin{array}{l}\text { Hypo- } \\
\text { thenar }\end{array}$ & $A P L$ \\
\hline $\mathrm{AG}$ & 69 & Male & $\begin{array}{l}\text { Motor neurone } \\
\text { disease }\end{array}$ & $\begin{array}{l}\mathbf{R} \\
25\end{array}$ & $\begin{array}{l}R \\
16\end{array}$ & $\begin{array}{l}\mathbf{R} \\
13\end{array}$ \\
\hline SB & 55 & Male & $\begin{array}{l}\text { Motor neurone } \\
\text { disease }\end{array}$ & $\begin{array}{l}L \\
10\end{array}$ & $\begin{array}{l}\mathrm{L} \\
36\end{array}$ & $\begin{array}{l}\mathrm{L} \\
13\end{array}$ \\
\hline
\end{tabular}

Table 3 Brachial plexu; lesion;-two patients

\begin{tabular}{|c|c|c|c|c|c|c|}
\hline \multirow[t]{2}{*}{ Patients } & \multirow{2}{*}{$\begin{array}{l}\text { Age } \\
(y r)\end{array}$} & \multirow[t]{2}{*}{ Sex } & \multirow[t]{2}{*}{ Diagnosis } & \multicolumn{3}{|c|}{ Count (units) } \\
\hline & & & & Thenar & $\begin{array}{l}\text { Hypo- } \\
\text { thenar }\end{array}$ & $A P L$ \\
\hline DC & 19 & Female & $\begin{array}{l}\text { Brachial } \\
\text { neuropathy on } \\
\text { right side }\end{array}$ & ${ }_{23}^{R}$ & $\begin{array}{l}R \\
515\end{array}$ & $\mathrm{R}_{53}$ \\
\hline FO & 33 & Male & $\begin{array}{l}\text { Traumatic lesion } \\
\text { of left brachial } \\
\text { plexus }\end{array}$ & $\mathrm{L}_{73}$ & $\begin{array}{l}L \\
125\end{array}$ & $\mathrm{~L}_{14}$ \\
\hline (Four m & onths & er, witho & linical improvement) & $\begin{array}{l}\mathrm{L} \\
205\end{array}$ & $\begin{array}{l}\mathrm{L} \\
110\end{array}$ & $\begin{array}{l}\mathrm{L} \\
106\end{array}$ \\
\hline
\end{tabular}

Figure 4 illustrates the number of motor units of control subjects and patients, according to age and nature of disease.

\section{MEAN INCREMENT (POOL)-CONTROL MEAN INCREMENT (POOL)-PATIENTS}

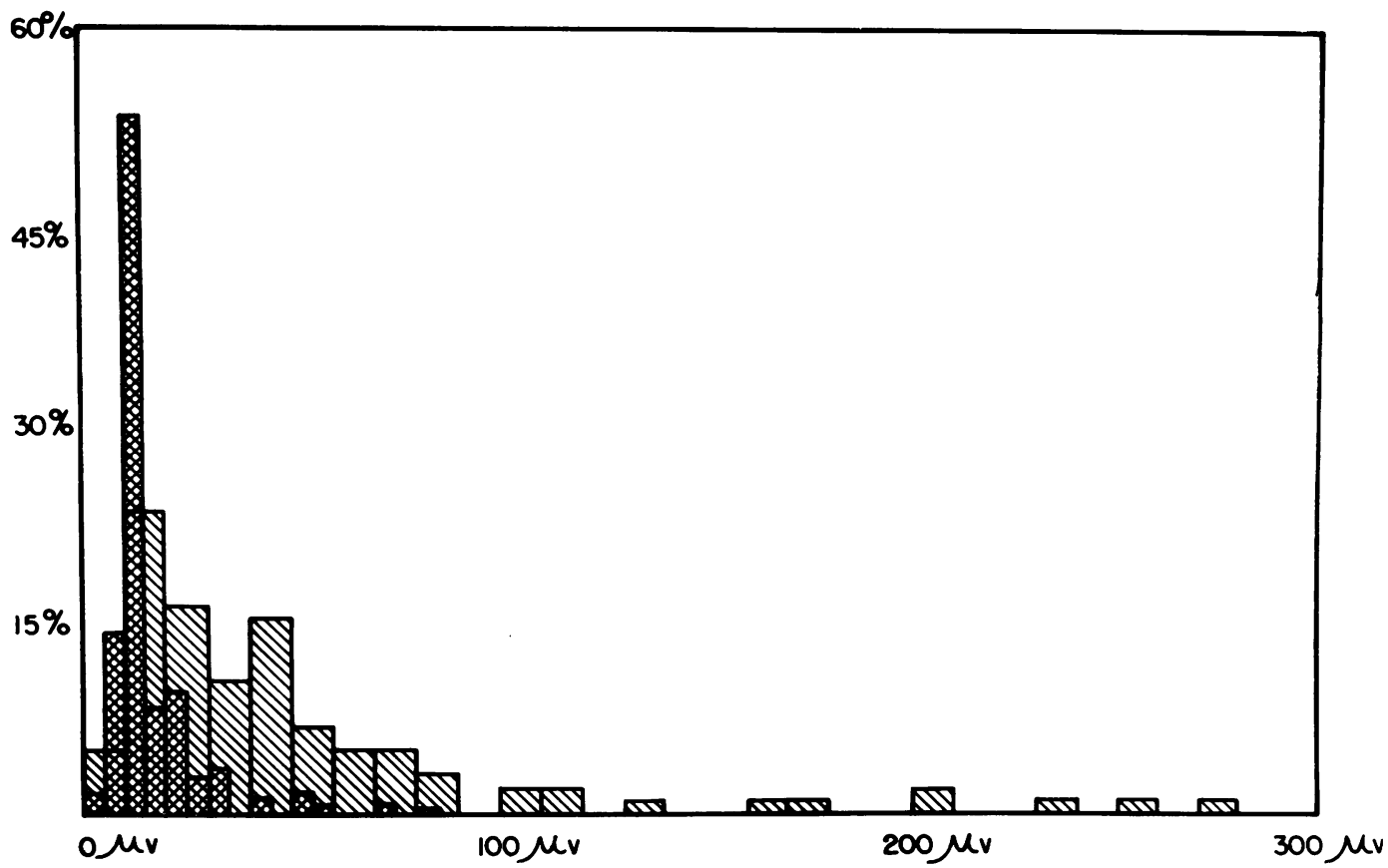

Fig. 3 Mean increment of patients and control subjects showing the higher steps in the patients with denervation of the APL muscle. 


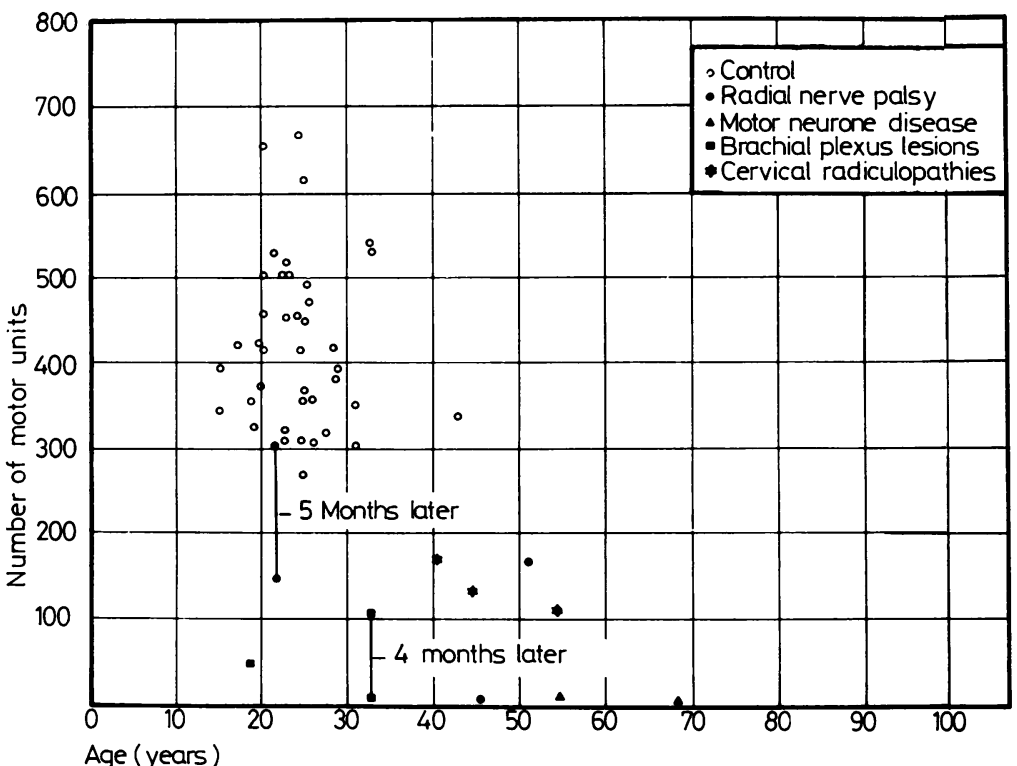

Fig. 4 Motor unit number in control subjects and patients. The lower normal limit is 270 motor units.
Table 4 Cervical radiculopathy-three patients

\begin{tabular}{lllllll}
\hline Patients & $\begin{array}{l}\text { Age } \\
(y r)\end{array}$ & Sex & Diagnosis & \multicolumn{3}{c}{ Count (units) } \\
\cline { 4 - 7 } & & & \multicolumn{3}{c}{ Thenar $\begin{array}{c}\text { Hypo- } \\
\text { thenar }\end{array}$} \\
\hline MJ & 45 & Female & Bilateral cervical & $\mathbf{R}$ & $\mathbf{R}$ & $\mathbf{R}$ \\
& & & radiculopathy & 100 & 285 & 133 \\
MW & 54 & Female & Right cervical & $\mathbf{R}$ & $\mathbf{R}$ & $\mathbf{R}$ \\
& & & radiculopathy & 84 & 320 & 111 \\
OC & 40 & \multirow{2}{*}{ Male } & $\begin{array}{l}\text { Right cervical } \\
\text { radiculopathy }\end{array}$ & $\mathbf{R}$ & $\mathbf{R}$ & $\mathbf{R}$ \\
& & & rad2 & 240 & 171 \\
\hline
\end{tabular}

\section{Discussion}

Sica et al. (1974) found that, on average, there were about 100 motor units in one of the small muscles within the thenar or hypothenar eminences. Their values were in agreement with the data of Feinstein et al. (1955) for other intrinsic muscles of the hand. The abductor pollicis longus, being larger than the intrinsic muscles, would be expected to have a greater number of motor units, and the observed value of $421 \pm 99$ appears reasonable. Similarly, the fact that this result is lower than the mean value of $957 \pm 254$ found by McComas (1977) for the soleus muscle would be predicted in view of the larger size of the latter muscle. A further indication of the probable accuracy of the method is the coefficient of variation (=SD mean), which compares favourably with values calculated from the data of McComas et al. (1971) and Sica et al. (1974) for other muscles. One possible source of error resulted from the proximity of the extensor pollicis brevis to APL since evoked potentials might have been recorded from both these radially innervated muscles. To minimise this possibility a small stigmatic electrode was used which was just large enough to cover the APL. Even if responses had been recorded from both muscles, the method would still have an empirical value since both muscles are supplied by the radial nerve and they share the same segmental innervation (C7 and C8). An indication of the clinical usefulness of this method is shown by the markedly reduced numbers of motor units in 10 patients with clinical and EMG evidence of radial nerve palsies, C7-C8 nerve root lesions, motor neurone disease, or brachial neuropathy.

\section{References}

Ballantyne, J. P., and Hansen, S. (1974). Computer method for the analysis of evoked motor unit potentials. Journal of Neurology, Neurosurgery, and Psychiatry, 37, 1187-1194.

Feinstein, B., Nyman, E., and Wohlfart, G. (1955). Morphological studies of motor units in normal human muscles. Acta Anatomica (Basel), 23, 127142.

McComas, A. J. (1977). Neuromuscular Function and Disorders. Butterworths: London.

McComas, A. J., Fawcett, P. R. W., Campbell, M. J., and Sica, R. E. P. (1971). Electrophysiological estimation of the number of motor units within a human muscle. Journal of Neurology, Neurosurgery, and Psychiatry, 34, 121-131.

Sica, R. E. P., McComas, A. J., Upton, A. R. M., and Longmire, D. (1974). Motor unit estimations in small muscles of the hand. Journal of Neurology, Neurosurgery, and Psychiatry, 37, 55-67. 